\section{Aborto: conhecimento e opinião de médicos dos serviços de emergência de Ribeirão Preto, São Paulo, Brasil, sobre aspectos éticos e legais}

\author{
Knowledge and opinions concerning legal \\ and ethical issues with abortion among physicians \\ working in emergency wards in Ribeirão Preto, \\ São Paulo, Brazil
}

David Câmara Loureiro 1 Elisabeth Meloni Vieira 2

\section{Introdução}

This study focused on the knowledge and opinions of physicians regarding legal and ethical aspects of abortion. A self-administered questionnaire was filled out by 57 physicians working in the emergency rooms of two hospitals in Ribeirão Preto, São Paulo State, Brazil in 2001. The questionnaire had 38 questions on general knowledge, legislation, and attitudes towards abortion. Interviewees' mean age was 28.3, most were females, $52.6 \%$ were single, $42.1 \%$ were married, $54.4 \%$ were Catholic, and $21 \%$ were Spiritists. Although most of the physicians had a good level of overall knowledge on abortion (70\%), one in five was not aware that abortion is the main cause of maternal mortality in Brazil. Most accepted the prevailing legal conditions for performing an abortion in Brazil but would also include fetal malformation incompatible with life, while opposing decriminalization of abortion on other grounds. Limited knowledge is revealed by misconceptions concerning enforcement of the prevailing legislation in practice. The study strongly suggests that many physicians lack knowledge or face difficulties in conforming to the Brazilian legislation on abortion.

Legal Abortion; Ethics; Health Services
O aborto provocado é uma das principais causas de morbi-mortalidade materna em países onde existem restrições legais ao aborto, especialmente quando são realizados por pessoal não qualificado 1 . As mulheres que não morrem podem ter complicações graves, como hemorragia, septicemia, peritonite e choque. Outras podem ter seqüelas físicas, como problemas ginecológicos e infertilidade, assim como maior chance de complicações em gestações subseqüentes 2 .

Apesar da falta de informações confiáveis, por suas conseqüências, e de ser uma das principais causas de internação hospitalar, existe o consenso de que o aborto provocado é um problema de saúde pública. No Brasil as estimativas mais recentes variam de 730 a 940 mil abortos anuais $3,4,5$, e o risco de morte ou lesões permanentes como seqüelas do aborto clandestino depende não só da clandestinidade em si, mas principalmente do poder aquisitivo da mulher. Não são as mulheres que freqüentam clínicas sofisticadas que engrossam as estatísticas de mortalidade por aborto, e sim aquelas cuja qualidade de vida já está marcadamente prejudicada pela dificuldade de acesso a alimentação, educação e cuidados básicos de saúde e que recorrem a medidas de alto risco ou se automedicam com drogas abortivas 6 .

A administração de misoprostol vem crescendo rapidamente no País desde 1990 ․ Al- 
guns autores atribuem a essa substância conseqüências bastante desastrosas, desde malformações fetais até mortes maternas por ruptura uterina. Entretanto, a impressão clínica é de que houve redução de complicações graves pós-aborto, desde que seu uso passou a ser mais amplamente difundido 7 .

$\mathrm{Na}$ ausência de uma oferta efetiva de meios contraceptivos no País, as políticas públicas em relação à saúde reprodutiva deixam a desejar: a esterilização abusiva de mulheres cada vez mais jovens, o uso de contraceptivos sem orientação médica e o aborto ilegal podem ser considerados exemplos de modernidade perversa na reprodução humana, com efeitos nocivos presumidos, mas ainda não investigados sobre a morbi-mortalidade feminina 8 . A política de direitos reprodutivos que deveria ter sido instituída pelo sistema de saúde desde 1983 não ocorreu até 1997, apesar da Constituição Federal de 1988 colocá-la como um direito básico do cidadão 9,10. Ainda hoje a oferta de contraceptivos é inadequada no Sistema Único de Saúde (SUS) 10. Como resultado, temos que, para muitas mulheres e adolescentes, faltam as condições sociais, culturais e políticas para ter arbítrio sobre a própria fertilidade. Isso é preocupante, porque a mesma atividade que põe a mulher em risco de uma gravidez não planejada também aumenta o risco de doenças sexualmente transmissíveis, incluindo a AIDS 11,12.

\section{A questão legal}

Todos os países do mundo desenvolveram regulamentações legais próprias para a prática do aborto. Cerca de $25 \%$ da população mundial vive em países onde o aborto é ilegal 13. Na América Latina, com exceção de Cuba e Guiana, o aborto enfrenta sérias restrições legais 5 .

O Código Penal Brasileiro 14 classifica o aborto entre os crimes contra a vida, que são subclasse dos crimes contra as pessoas. São passíveis de pena: a gestante que provoca o abortamento em si mesma (auto-abortamento, artigo 123) ou consente que outrem lho provoque (abortamento consentido, artigo 124) e a pessoa que provoca o abortamento com ou sem o consentimento da paciente (artigos 125 e 126). Prevê-se o agravamento da pena quando o crime é praticado em menores ou alienados (artigo 125) ou se realizado mediante violência (artigo 128); a pena também é aumentada se há lesões graves ou morte (artigo 126). Não se pune o aborto praticado por médico se não há outro meio de salvar a vida da gestante ou em caso de gravidez resultante de estupro (artigo 128). Assim mesmo, a expressão "não se pune” dá margem para se considerar que, para a legislação, qualquer forma de aborto continua sendo crime, ainda que não passível de punição 15 . A lei não cogita tampouco doenças de transmissão genética, feto malformado, ingestão de fármaco teratogênico, virose contraída durante a organogênese. As indicações maternas, na visão obstétrica 16 da prática atual, têm em mira evitar o agravamento da doença da gestante, enquanto a lei brasileira subentende que somente quando a piora caminha para o óbito é a intervenção permitida. Isso significa que, para a sociedade brasileira, o direito à vida deve ser protegido desde a concepção, como especificado no artigo 4o do Código Civil de 191617. Durante a elaboração da Constituição de 1988 , um dos pontos mais discutidos foi a introdução ou não da idéia de "princípio de defesa da vida desde a concepção" que acabou não sendo incluída. Isto poderia permitir, segundo alguns, o debate sobre a modificação do Código Penal 17.

\section{A questão ética}

Nessa matéria nem mesmo os médicos estão imunes ao conflito dos valores fundamentais, pois não existe um critério comum à humanidade. Segundo Dallari 18, a deontologia médica nacional recusou-se a discutir o assunto e optou apenas por vedar a prática de atos proibidos pela legislação do País, exigindo dos médicos que cumpram legislação específica nos casos de abortamento, de acordo com os artigos 42 e 43 do Código de Ética Médica 19. Isto não ocorreu internacionalmente, já que a 24a Assembléia Geral da Associação Médica Mundial, em Oslo, em 1970, adotou uma declaração sobre o aborto terapêutico que leva em conta a diversidade de respostas ao conflito de interesses vitais da mãe e do filho que vai nascer e considera não ser dever do médico determinar as regras e as atitudes a respeito da opinião sobre a criança, mas proteger seus pacientes e salvaguardar os direitos médicos na sociedade.

O Código de Ética Médica 19 veda ao médico "acumplicitar-se com os que exercem ilegalmente a medicina, ou com profissionais ou instituições médicas que pratiquem atos ilícitos" (artigo 38), portanto o médico não pode fornecer endereço de clínica de aborto ou orientar a compra de medicamentos abortivos, mesmo sem prescrevê-los. Se o médico tiver conhecimento de clínica de aborto ou de colegas que fornecem endereços ou que orientam suas clientes para práticas abortivas e não os denunciar, estará violando o artigo 19 do Código de Ética Médica 20. Sabe-se por notícias da mídia ${ }^{21}$ 
que alguns hospitais universitários interromperam gestações, à revelia da lei, em casos de graves malformações fetais, alegando razões humanitárias. Ao mesmo tempo, diversos juízes em vários estados do Brasil têm autorizado judicialmente o aborto em caso de malformação incompatível com a vida. Embora a justiça seja lenta nesses casos que exigem intervenção rápida, está criada jurisprudência que reforça a necessidade de reforma da legislação, já que o Código Penal de 1940 não pode abranger esta questão, posto que naquela época não havia tecnologia para esse tipo de diagnóstico prénatal 13 .

A sociedade atual pede aos médicos que sejam sua própria consciência nas questões de reprodução humana. Entretanto, eles têm as mesmas limitações do meio a que pertencem e as mesmas ambigüidades, e estão tolhidos pela hipocrisia dos costumes 16 . Até pouco tempo, o aborto não podia ser discutido nas casas, nem nos meios de comunicação, nem mesmo nas escolas de medicina.

Sobre o sigilo da paciente que recorre ao hospital por complicação do aborto provocado, o capítulo IX do Código de Ética Médica 19 referente ao segredo médico veda ao médico "revelar fato de que tenha conhecimento em virtude do exercício de sua profissão, salvo por justa causa, dever legal ou autorização expressa do paciente" (artigo 102). A violação do segredo profissional, segundo a seção IV do Código Penal 14 (artigo 154), prevê detenção de três meses a um ano, ou multa, para a revelação do segredo sem justa causa. Não cabe, portanto, ao médico denunciar o "crime" cometido pela mulher, como crêem alguns, mas assisti-la e orientá-la convenientemente para que se previna a repetição do fato.

\section{O aborto legal}

Sabe-se que a maior parte dos serviços de saúde não está preparada para atender as mulheres vítimas de violência e, particularmente, os casos de estupro. Muitas grávidas vítimas de estupro provavelmente ainda não têm acesso ao aborto legal, haja vista o alto número de estupros contra a baixa solicitação dos poucos serviços especializados 22,23. Atualmente, a lei não exige boletim de ocorrência nem laudo de perícia para a realização do aborto legal; no entanto, ele é habitualmente exigido nos serviços médicos. Este fato é condizente com o temor dos médicos de serem acusados pela justiça de estarem interrompendo uma gestação que na realidade não foi resultado de estupro. Esse medo não é justificado, porque, caso o médico se- ja induzido a erro ao indicar aborto legal, justificado pelas circunstâncias, estará caracterizada a Descriminante Putativa prevista no artigo 20, Parágrafo 1o do Código Penal, e o médico ficará isento de pena.

\section{O que sabem e pensam} os médicos sobre o aborto?

Observando-se esses fatos, é digna a dúvida se o profissional médico está preparado para atender as mulheres que abortam clandestinamente, e se a qualidade do serviço prestado não é prejudicada pelo preconceito. O envolvimento médico nesses assuntos é inevitável, independentemente do seu posicionamento ideológico. Curiosamente, embora aos médicos caiba um papel de destaque neste problema, são poucos os estudos que se preocupam em saber como esse grupo vivencia o confronto entre as práticas reais e a proibição legal. Um deles 24 baseava-se em um questionário enviado aos sócios da Federação Brasileira de Ginecologia e Obstetrícia. A condição "permitir o aborto sob o simples desejo expresso pela mulher casada, com aquiescência do marido" foi aceita por 13,8\% dos médicos em 1977 e por 19\% em 1987. Em outro estudo, com estudantes de medicina e de direito, Meira \& Ferraz 15 obtiveram $47,7 \%$ e $49,3 \%$, respectivamente, a favor da descriminalização do aborto.

Uma pesquisa realizada com médicos de hospitais públicos do Rio de Janeiro, por Giffin 8 , obteve como resultado que a maioria considerava o aborto um problema de saúde pública e defendia sua liberação, entendida como forma de diminuir a morbi-mortalidade, principalmente das mulheres mais pobres; $44 \%$ sugeriram a descriminalização do aborto em casos em que a mulher não quer ter o filho e $45 \%$ no caso de suspeita ou comprovação de malformação. A autora concluiu que, embora não participe da discussão pública em torno da descriminalização, a categoria médica é a favor dela.

Motivado pela importância da visão médica no debate político e na opinião pública e pela escassez desse tipo de investigação, especialmente em Ribeirão Preto, São Paulo, o presente estudo teve como objetivo investigar o conhecimento e as opiniões dos médicos sobre os aspectos legais e éticos do aborto, sabendo-se que o quadro de aborto parece ser uma causa de internação bastante comum no município. Em 1997 e 1998 houve, nos hospitais de Ribeirão Preto, respectivamente 1.326 e 1.443 casos de internação com esse diagnóstico, dos quais apenas $1,5 \%$ e $1,9 \%$ foram classificados como abortos espontâneos 25 . 


\section{Material e métodos}

Este estudo caracteriza-se como uma investigação de corte transversal, com a aplicação de um questionário auto-administrado a médicos que trabalham nas salas de emergência de dois hospitais da cidade que atendem todos os pacientes obstétricos do SUS e que recebem cerca de $70 \%$ dos casos de complicações por aborto na cidade 25 .

No total, foram entrevistados 57 médicos, inclusive médicos residentes, já que os dois serviços são hospitais escolas. Estes compõem o universo de todos os médicos trabalhando nas salas de emergência, no período de setembro a novembro de 2001, na especialidade de Ginecologia/Obstetrícia. Do questionário auto-aplicável constavam 38 perguntas divididas em quatro secções: (1) dados pessoais, como idade, sexo, tempo de formado, escola da formatura, religião, estado marital e renda; (2) conhecimentos gerais sobre aborto, com nove afirmações do tipo verdadeiro/falso e duas perguntas de múltipla escolha; (3) conhecimentos gerais sobre a legislação do aborto, com 16 afirmações do tipo verdadeiro/falso; (4) opiniões sobre o aborto com nove questões formadas por 27 assertivas.

Os questionários foram pré-testados, aplicados previamente a um grupo de dez alunos do 6 o ano de medicina, que foram solicitados a tecer críticas sobre a formulação das perguntas visando testar a clareza da linguagem e a objetividade do instrumento.

Os questionários auto-aplicáveis foram respondidos em cerca de dez minutos na presença do pesquisador, no local de trabalho do entrevistado, nos períodos de menor movimento no serviço, após ter sido esclarecido e assinado o termo de consentimento de participação no estudo. Este projeto de pesquisa foi aprovado pelo Comitê de Ética em Pesquisa do Hospital das Clínicas, Faculdade de Medicina de Ribeirão Preto, Universidade de São Paulo.

Os dados foram analisados utilizando-se o pacote estatístico STATA, tendo-se realizado análise de freqüência simples das variáveis e busca de associação, utilizando o teste do quiquadrado e exato de Fisher. A hipótese de associação estatística foi aceita quando se encontrou p igual ou menor que 0,05 .

\section{Resultados}

A idade dos entrevistados variou de 23 a 54 anos; a média encontrada foi de 28,3 e a mediana, de 27 (desvio padrão de 5,83). Dos 57 respondentes a maioria era do sexo feminino;
$52,6 \%$ eram solteiros; $42 \%$, casados; e $3,5 \%$ referiram que moravam juntos. Havia apenas um viúvo e nenhum separado ou divorciado.

A maioria era católica $(54,4 \%)$ ou espírita (21\%); 11\% referiram não ter religião; 5,3\% eram evangélicos ou crentes; $5,3 \%$ marcaram outra religião não especificada; e 3,5\% eram protestantes. Perguntados sobre o hábito de comparecer a cerimônias religiosas, a maioria comparece menos de uma vez por mês (28\%) ou não freqüenta (26\%); 19,3\% vão ao menos uma vez por semana; $14 \%$, uma vez por mês; e $1,8 \%$, duas vezes por semana.

A renda per capita mensal variou de $\mathrm{R} \$ 500,00$ a $\mathrm{R} \$ 5.000,00$, com média de $\mathrm{R} \$ 1.615,00$, desvio padrão de R\$ 761,00 e mediana de $\mathrm{R} \$ 1.300,00$.

Dos 57 entrevistados, $81 \%$ trabalhavam na unidade de emergência do Hospital das Clínicas, Faculdade de Medicina de Ribeirão Preto, Universidade de São Paulo, e 19\%, na Santa Casa. Cerca de $20 \%$ eram médicos contratados e os $80 \%$ restantes, médicos residentes. Destes, $31,6 \%$ estavam no 1 o ano de residência; $28 \%$, no 2 o ano; e $21 \%$, no 3 o ano. Optamos por convencionar um ano de formado para o residente do 1 o ano, dois anos para os residentes do 20 ano e três anos para os do 3o ano, já que a coleta de dados deu-se no fim do ano. A média de anos de formado foi de 3,75 anos e a mediana, de dois anos, com variação de 1 a 29 anos. Do total de entrevistados $42 \%$ eram formados pela Faculdade de Medicina de Ribeirão Preto; 15\%, pela Faculdade de Medicina do Triângulo Mineiro; 15\%, pela Universidade Federal de Uberlândia; e $27 \%$, por várias outras faculdades. Cinco pessoas não responderam a esta questão (Tabela 1).

\section{Informação sobre o aborto}

A maioria $(96,5 \%)$ afirmou ter tido aula sobre aborto na graduação; $52 \%$, nas disciplinas de Ginecologia/Obstetrícia (GO) e de Medicina Legal; $34 \%$, apenas na disciplina de GO; $9 \%$, em GO, Medicina Legal e Medicina Social; e 4\%, em GO e Medicina Social. Uma pessoa respondeu que não teve esta aula e outra não respondeu.

\section{Conhecimentos gerais sobre o aborto}

A maior parte dos entrevistados respondeu corretamente a maioria das nove afirmações do tipo verdadeiro/falso. Entretanto, $21 \%$ - ou seja, um em cada cinco médicos - estão desinformados sobre o fato de ser o aborto responsável por grande parte das mortes maternas; quase a mesma proporção (23\%) respondeu incorretamente que as mulheres que mais recorrem ao 
aborto já excederam o número de filhos; $37 \%$ dos entrevistados responderam incorretamente que o aborto provocado não está entre as principais causas de mortalidade materna em Ribeirão Preto (Tabela 2).

Solicitados a numerar corretamente em ordem decrescente as três primeiras causas de mortalidade materna (a saber: complicações relacionadas com a gravidez, complicações do puerpério e gravidez terminada em aborto), $39 \%$ não acertaram nenhuma das três e $46 \%$ acertaram apenas uma na ordem correta.

Sobre os três métodos contraceptivos mais utilizados no Brasil (esterilização feminina, pílula e preservativo masculino), em qualquer ordem, $18,5 \%$ (dez) acertaram os três dentre as seis opções, $76 \%$ (41) acertaram duas e 6\% (três) acertaram apenas uma. Três pessoas não responderam

Estas duas últimas questões foram computadas com as nove afirmações da Tabela 2 para formar uma escala de conhecimento. De um total possível de 15 pontos, o índice de acerto variou de cinco $(3,5 \%)$ a 14 pontos $(1,8 \%)$. A média foi de 10,7; a mediana foi igual a 11; e o desvio padrão, igual a 1,69. Consolidados os números de pontos atingidos em três níveis - baixo (5 a 9 pontos), médio ( 10 e 11 pontos) e alto (12 a 14 pontos) -, observamos que $35 \%$ (20) dos entrevistados demonstraram ter um conhecimento geral sobre aborto alto e $49 \%$ (28), um conhecimento médio. Apenas 16\% (nove) revelaram ter baixo conhecimento geral sobre o aborto. Não foi encontrada associação entre esta escala de conhecimento geral e sexo, idade, local de trabalho, tempo de trabalho, faculdade de origem, estado marital ou religião.

\section{Conhecimentos sobre a lei do aborto}

De acordo com o Código Penal 15, os entrevistados julgaram com acerto que não se pune aborto praticado por médico quando a gestante apresenta risco de vida $(96,5 \%)$ e quando a gravidez resulta de estupro (93\%); e que o aborto deve ser punido se há malformação comprovada $(82,5 \%)$, se a gestante é menor de idade (93\%), se a mulher não deseja ter o filho (93\%) e se há risco para a saúde da gestante $(66,7 \%)$ (Tabela 3).

Para que fosse realizado o aborto legal, $74 \%$ erraram ao afirmar que é necessário o boletim de ocorrência e $65 \%$ ao afirmar que é necessário o laudo do Instituto Médico Legal (IML); 74\% acertaram ao afirmar que não é necessário o consentimento do marido. Apenas 10,5\% acertaram os três itens da questão e $12 \%$ erraram todos os itens.

Tabela 1

Características dos médicos ginecologistas obstetras trabalhando nas unidades de emergência de dois hospitais de Ribeirão Preto, São Paulo, Brasil, em 2001.

\begin{tabular}{|c|c|c|}
\hline & $\mathbf{n}$ & $\%$ \\
\hline \multicolumn{3}{|l|}{ Idade (anos) } \\
\hline $23-25$ & 16 & 28,0 \\
\hline $26-29$ & 30 & 52,6 \\
\hline $30-54$ & 11 & 19,2 \\
\hline \multicolumn{3}{|l|}{ Sexo } \\
\hline Masculino & 25 & 43,9 \\
\hline Feminino & 32 & 56,1 \\
\hline \multicolumn{3}{|l|}{ Estado marital } \\
\hline Solteiros & 30 & 52,6 \\
\hline Casados & 24 & 42,1 \\
\hline Moram juntos & 2 & 3,5 \\
\hline Viúvos & 1 & 1,8 \\
\hline \multicolumn{3}{|l|}{ Religião } \\
\hline Católicos & 31 & 54,4 \\
\hline Espíritas & 12 & 21,1 \\
\hline Evangélicos & 3 & 5,3 \\
\hline Protestantes & 2 & 3,5 \\
\hline Outras & 3 & 5,3 \\
\hline Sem religião & 6 & 10,5 \\
\hline \multicolumn{3}{|l|}{ Renda per capita (em reais) } \\
\hline $500-1.200$ & 26 & 45,6 \\
\hline $1.300-2.200$ & 22 & 38,6 \\
\hline $2.300-5.000$ & 29 & 15,8 \\
\hline \multicolumn{3}{|l|}{ Local de trabalho } \\
\hline Hospital 1 & 46 & 80,7 \\
\hline Hospital 2 & 11 & 19,3 \\
\hline \multicolumn{3}{|l|}{ Condição de trabalho } \\
\hline Residentes & 46 & 80,7 \\
\hline Contratados & 11 & 19,3 \\
\hline \multicolumn{3}{|l|}{ Tempo de formado (anos) } \\
\hline 1 & 18 & 31,6 \\
\hline 2 & 16 & 28,1 \\
\hline 3 & 12 & 21,1 \\
\hline $4-29$ & 11 & 19,1 \\
\hline \multicolumn{3}{|l|}{ Escola médica } \\
\hline $\begin{array}{l}\text { Faculdade de Medicina } \\
\text { de Ribeirão Preto }\end{array}$ & 22 & 42,3 \\
\hline Triângulo Mineiro & 16 & 30,8 \\
\hline Outras & 14 & 26,9 \\
\hline \multicolumn{3}{|l|}{ Aula sobre aborto } \\
\hline $\begin{array}{l}\text { Ginecologia/Obstetrícia } \\
\text { e Medicina Legal }\end{array}$ & 29 & 51,8 \\
\hline Ginecologia/Obstetrícia & 19 & 33,9 \\
\hline $\begin{array}{l}\text { Ginecologia/Obstetrícia, } \\
\text { Medicina Legal e Medicina Social }\end{array}$ & 5 & 12,5 \\
\hline
\end{tabular}


Conhecimentos gerais sobre o aborto entre os médicos ginecologistas obstetras trabalhando nas unidades de emergência de dois hospitais de Ribeirão Preto, São Paulo, Brasil, em 2001.

\begin{tabular}{|c|c|c|c|c|}
\hline & \multicolumn{2}{|c|}{ Verdadeiro } & \multicolumn{2}{|c|}{ Falso } \\
\hline & $\mathrm{n}$ & $\%$ & $\mathrm{n}$ & $\%$ \\
\hline $\begin{array}{l}\text { Nos países em desenvolvimento o aborto é responsável por grande } \\
\text { parte das mortes maternas }(V)\end{array}$ & 45 & 78,9 & 12 & 21,1 \\
\hline $\begin{array}{l}\text { O aborto repetido por dilatação e curetagem pode trazer riscos } \\
\text { a uma futura gestação }(V)\end{array}$ & 55 & 96,5 & 2 & 3,5 \\
\hline $\begin{array}{l}\text { Sobre as mulheres que mais recorrem ao aborto provocado no Brasil, } \\
\text { elas costumam ter excedido o número desejado de filhos (F) }\end{array}$ & 13 & 22,8 & 44 & 77,2 \\
\hline $\begin{array}{l}\text { Sobre as mulheres que mais recorrem ao aborto provocado no Brasil, } \\
\text { a maioria é jovem (V) }\end{array}$ & 56 & 98,2 & 1 & 1,8 \\
\hline $\begin{array}{l}\text { O acesso eficiente ao planejamento familiar contribui para prevenir } \\
\text { o aborto provocado }(\mathrm{V})\end{array}$ & 55 & 96,5 & 2 & 3,5 \\
\hline O aborto é um problema de saúde pública $(\mathrm{V})$ & 55 & 100,0 & - & - \\
\hline O acesso ao planejamento familiar promovido no Brasil é adequado (F) & 2 & 3,5 & 53 & 96,4 \\
\hline O aborto não deve ser utilizado como método de planejamento familiar (V) & 53 & 96,4 & 2 & 3,6 \\
\hline $\begin{array}{l}\text { O aborto provocado está entre as principais causas de mortalidade materna } \\
\text { em Ribeirão Preto }(V)\end{array}$ & 34 & 63,0 & 20 & 37,0 \\
\hline
\end{tabular}

Tabela 3

Conhecimento sobre a legislação do aborto entre os médicos ginecologistas obstetras trabalhando nas unidades de emergência de dois hospitais de Ribeirão Preto, São Paulo, Brasil, em 2001.

\begin{tabular}{|c|c|c|c|c|}
\hline & \multicolumn{2}{|c|}{ Verdadeiro } & \multicolumn{2}{|c|}{ Falso } \\
\hline & $\mathrm{n}$ & $\%$ & $\mathrm{n}$ & $\%$ \\
\hline \multicolumn{5}{|l|}{$\begin{array}{l}\text { De acordo com o artigo } 154 \text { do Código Penal, não se pune o aborto } \\
\text { praticado por médico em algumas situações }\end{array}$} \\
\hline A gestante corre risco de vida $(\mathrm{V})$ & 55 & 96,5 & 2 & 3,5 \\
\hline A gravidez resulta de estupro $(\mathrm{V})$ & 53 & 93,0 & 4 & 7,0 \\
\hline Há malformação comprovada (F) & 10 & 17,5 & 47 & 82,5 \\
\hline A gestante é menor de idade $(F)$ & 4 & 7,0 & 53 & 93,0 \\
\hline A mulher não deseja ter o filho $(F)$ & 4 & 7,0 & 53 & 93,0 \\
\hline Há risco para a saúde da gestante (F) & 19 & 33,0 & 38 & 67,0 \\
\hline \multicolumn{5}{|l|}{ Para que seja realizado o aborto legal } \\
\hline É necessário o boletim de ocorrência (F) & 42 & 73,7 & 15 & 26,3 \\
\hline É necessário o laudo do Instituto Médico Legal (F) & 37 & 64,9 & 20 & 35,1 \\
\hline É preciso o consentimento do marido $(\mathrm{F})$ & 15 & 26,3 & 42 & 73,7 \\
\hline \multicolumn{5}{|l|}{ Quando há suspeita de aborto clandestino o médico } \\
\hline Deve denunciar à polícia (F) & 29 & 50,9 & 28 & 49,1 \\
\hline Não deve denunciar de modo algum (F) & 11 & 19,3 & 46 & 80,7 \\
\hline Não pode denunciar salvo em justa causa (V) & 28 & 49,1 & 29 & 50,9 \\
\hline \multicolumn{5}{|l|}{ A suspeita de aborto clandestino deve ser anotada no prontuário? } \\
\hline Sim, porque é necessário à denúncia $(F)$ & 21 & 37,5 & 35 & 62,5 \\
\hline Não, porque é informação sigilosa (F) & 25 & 44,6 & 31 & 55,4 \\
\hline Sim, porque é necessário à correta condução do atendimento (V) & 21 & 36,8 & 36 & 63,2 \\
\hline A denúncia do aborto provocado fere a lei do segredo profissional? (V) & 39 & 68,4 & 18 & 31,6 \\
\hline
\end{tabular}


Sobre a suspeita de aborto clandestino, $51 \%$ dos médicos erraram ao dizer que o médico deve ("sempre") denunciar à polícia, $81 \%$ acertaram em marcar falso o item "não deve denunciar de modo algum" e 51\% erraram ao apontar como falso o item "não pode denunciar salvo em justa causa”, o qual está correto. Apenas $30 \%$ acertaram os três itens.

Sobre a anotação ou não da suspeita de aborto clandestino no prontuário médico, a maioria acredita que não deve ser anotada: $62,5 \%$ acertaram ao marcar falso na justificativa "ser necessário à denúncia" e 55\% acertaram ao marcar falso o item "não, porque é informação sigilosa”. Apenas 37\% acertaram ao responder que deve ser anotada em prontuário, pois é necessário à correta condução do caso. Apenas nove entrevistados (16\%) acertaram toda a questão. Uma pessoa deixou de responder dois itens desta questão.

Em relação à assertiva segundo a qual a denúncia do aborto fere a lei do segredo profissional, $68 \%$ a consideraram verdadeira acertadamente, enquanto $32 \%$ a julgaram falsa.

Consolidadas essas questões sobre as leis do aborto no Brasil, verificamos que o índice de acertos variou de 7 a 14 pontos, de um máximo de 16 pontos possíveis, com média de 10,5 ; mediana de 11 e desvio padrão de 1,69. Consolidado o número de pontos atingido nos três níveis - baixo (4 a 9 pontos), médio (10 e 11 pontos) e alto (12 a 14 pontos) -, observamos que $22 \%$ (13) dos entrevistados demonstraram ter um nível alto, 46\% (26), nível médio e 31,5\% (18) revelaram ter baixo conhecimento sobre as leis do aborto. Não foi encontrada associação entre essa escala de conhecimento e sexo, idade, local de trabalho, tempo de trabalho, faculdade de origem, estado marital ou religião.

\section{Opiniões sobre o aborto}

A maior parte dos médicos entrevistados é favorável ao aborto legal. A maioria dos entrevistados ampliaria o acesso ao aborto legal em uma circunstância: no caso de malformação incompatível com a vida. Isto pode ser observado na Tabela 4 : $84 \%$ concordam com o aborto em situação de estupro; $86 \%$, em caso de risco de vida; e $82 \%$, em casos de malformação incompatível com a vida. Uma porcentagem menor de entrevistados (66\%) concorda com mudanças na lei, ampliando os tipos de casos nela previstos (66\%). Embora a maioria $(47,4 \%)$ aceite o aborto legal nos casos de risco de saúde, 35\% não aceitariam. Mais da metade dos entrevistados (55\%) discorda do aborto para casos de malformação compatível com a vida.
A maioria (70\%) discorda que o aborto deva ser totalmente descriminalizado e a maioria não aceita o aborto pelo desejo da mulher $(77 \%)$, por dificuldades sócio-econômicas $(82,5 \%)$ ou gravidez na adolescência (58\%). Observou-se uma porcentagem próxima de um terço na escolha do "nem concordo, nem discordo" das seguintes assertivas: não aceitar o aborto em nenhuma circunstância (29\%), mal-formação compatível com a vida, gravidez na adolescência $(33 \%)$ e mudar a lei do aborto (29\%). Ou seja, um em cada três respondentes não tem opinião formada sobre o aborto nessas circunstâncias.

Quase $60 \%$ concordam que o médico que pratica o aborto ilegal deva ser punido, mas cerca da metade deles (51\%) discorda em realizar denúncia.

Se o aborto fosse descriminalizado, apenas $17,5 \%$ concordariam em realizá-lo profissionalmente, $23 \%$ não têm opinião sobre isto e quase $60 \%$ não o realizaria. Maior número (72\%) discorda que pudesse praticar o aborto em uma situação pessoal e menos de $10 \%$ utilizariam o aborto.

Apesar dessa grande rejeição ao aborto, $75 \%$ afirmam que isso não afeta a relação médico-paciente, discordando da afirmação que mantêm o mínimo de contato necessário, $79 \%$ referem que se aproximam ao máximo e esclarecem as dúvidas da mulher, $68 \%$ discordam de sentir raiva da mulher sabendo que ela praticou um aborto e $45 \%$ dizem não reprovar a mulher que praticou o aborto. Em relação a um pedido de aborto, $90 \%$ recusariam e $10 \%$ não sabem. A maioria (98\%) pensa que o médico deve esclarecer o problema e tentar reverter o desejo de aborto (77\%). A maioria não indicaria remédio abortivo ( $80 \%)$ e $75 \%$ não indicariam outro médico. Todos os itens da escala de opinião sobre o aborto apresentaram uma média de covariância de 0,214571 e um alfa de Crombach de 0,8713, mostrando alta consistência interna entre as perguntas.

Consolidadas essas questões de um total possível de 135 pontos, houve variação de 63 a 132, média de 96,6 e mediana de 27 , e desvio padrão de 15,34. Feita uma estratificação dos níveis de pontos em correspondência com o nível de aceitação do aborto, observamos que a maioria dos entrevistados (49\%) teve uma média aceitação do aborto, quase um terço (30\%) teve baixa aceitação e $21 \%$ dos entrevistados apresentaram alta aceitação ao aborto. 
Opiniões dos médicos ginecologistas obstetras trabalhando nas unidades de emergência de dois hospitais de Ribeirão Preto, São Paulo, Brasil, em 2001.

\begin{tabular}{|c|c|c|c|c|}
\hline & $\mathrm{n}$ & $C(\%)$ & NC/ND (\%) & D (\%) \\
\hline \multicolumn{5}{|l|}{ Quando você é favorável ao aborto provocado? } \\
\hline Nunca & 56 & 7,2 & 28,6 & 64,3 \\
\hline Estupro & 56 & 83,9 & 5,4 & 10,8 \\
\hline Risco de vida & 57 & 86,0 & 1,8 & 12,3 \\
\hline Risco de saúde & 57 & 47,4 & 17,5 & 35,0 \\
\hline Malformação compatível com a vida & 56 & 16,1 & 28,6 & 55,4 \\
\hline Malformação incompatível com a vida & 57 & 82,4 & 5,3 & 12,3 \\
\hline A mulher não deseja o filho & 57 & 10,6 & 12,3 & 77,2 \\
\hline Dificuldades socioeconômicas & 57 & 5,3 & 12,3 & 82,5 \\
\hline Gravidez na adolescência & 57 & 8,8 & 33,3 & 57,9 \\
\hline A lei do aborto deve ser mudada & 56 & 66,0 & 28,6 & 5,4 \\
\hline O aborto deve ser totalmente descriminalizado & 57 & 15,8 & 14,0 & 70,2 \\
\hline Deveria haver ampliação dos casos permitidos por lei & 56 & 66,0 & 28,6 & 5,4 \\
\hline Se fosse descriminalizado praticaria profissionalmente & 57 & 17,5 & 22,8 & 59,6 \\
\hline Se fosse descriminalizado praticaria pessoalmente & 57 & 8,8 & 19,3 & 72,0 \\
\hline Os médicos que praticam aborto ilegal deveriam ser punidos & 57 & 59,7 & 21,1 & 19,3 \\
\hline Denunciaria os médicos que praticam aborto ilegal & 57 & 12,3 & 36,8 & 51,0 \\
\hline $\begin{array}{l}\text { Considera crime recomendar medicamento abortivo } \\
\text { mesmo sem prescrevê-lo }\end{array}$ & 57 & 63,2 & 14,0 & 22,8 \\
\hline \multicolumn{5}{|l|}{ Quando atende um caso de aborto: } \\
\hline Mantém o mínimo de contato necessário & 57 & 12,3 & 12,3 & 75,4 \\
\hline Aproxima-se ao máximo e esclarece as angústias da mulher & 57 & 8,0 & 7,0 & 78,9 \\
\hline Sente raiva da mulher & 57 & 8,8 & 22,8 & 68,4 \\
\hline Reprova seu ato & 57 & 33,3 & 21,1 & 45,6 \\
\hline A ilegalidade cria situações difíceis para os médicos & 57 & 80,7 & 12,3 & 7,0 \\
\hline \multicolumn{5}{|l|}{ Quando o obstetra recebe um pedido de aborto ilegal ele deve: } \\
\hline Atendê-la & 56 & 0,0 & 10,7 & 89,3 \\
\hline Tentar reverter o desejo & 56 & 76,7 & 12,5 & 10,7 \\
\hline Esclarecer o problema & 56 & 98,2 & 1,8 & 0,0 \\
\hline Indicar outro médico & 56 & 8,9 & 16,1 & 75,0 \\
\hline Indicar remédio abortivo & 55 & 1,8 & 18,2 & 80,0 \\
\hline
\end{tabular}

$\mathrm{n}=$ número de respondentes da pergunta $\mathrm{C}=$ concorda; $\mathrm{NC} / \mathrm{ND}=$ não concorda nem discorda; $\mathrm{D}=$ discorda.

\section{Discussão}

Pode-se caracterizar que a maioria dos médicos respondentes desta pesquisa tem um nível médio de conhecimento geral sobre aborto. Tratando-se de médicos especialistas, é importante frisar que seria desejável uma melhora desse nível de conhecimento, em particular nos aspectos identificados como mais falhos: a epidemiologia do aborto, seu peso na mortalidade materna e - ponto crucial - sua prevenção por meio de contracepção.

Em relação à legislação sobre o aborto, observou-se grande porcentagem de profissio- nais com baixo conhecimento (31,5\%). Embora alguns aspectos das leis sejam bem conhecidos, os itens problemáticos para grande parcela dos entrevistados são aqueles relacionados com a aplicação prática da lei do aborto. Embora um dos hospitais pesquisados seja considerado pelo Ministério da Saúde como referência para o aborto legal no Brasil, não parecem existir condições que possibilitem o aprendizado do atendimento ao aborto legal. Ou seja, ou o hospital não realiza o procedimento (aborto legal) ou, se realiza, não tem o envolvimento de médicos residentes em sua prática. Se não realiza, deveria ao menos estimular o ensino 
teórico. Encontrou-se alta porcentagem de médicos que possuem conceitos errôneos envolvendo questões básicas no atendimento do aborto legal, tal como pedir ou não o boletim de ocorrência e solicitar laudo para o IML. Embora tenham conhecimento razoável sobre as leis do aborto, a maioria dos médicos demonstrou não conhecer aspectos práticos importantes de sua aplicação. Apesar de muitos apresentarem uma atitude positiva em relação ao aborto legal, acredita-se que terão problemas na aplicação da lei por causa de conceitos errôneos, o que pode resultar em entrave na obtenção do procedimento pela mulher, ferindo assim seus direitos previstos em lei.

No atendimento de casos de aborto provocado, para grande porcentagem de médicos duas questões básicas foram identificadas como problemáticas: a anotação no prontuário e o sigilo profissional. Os médicos temem denunciar a mulher quando anotam no prontuário e/ou não conhecem ou não parecem estar seguros sobre a lei do segredo profissional. O preconceito no meio médico existe e, nesse contexto, o médico tem até medo de expressar sua opinião, omitindo-se ou esquivando-se do tema tal como refere Vieira 10 . O medo, o preconceito e a desconfiança da sociedade são

\section{Resumo}

Este estudo tem por objetivo investigar o conhecimento e as opiniões dos médicos sobre os aspectos legais e éticos do aborto. Utilizou-se um questionário auto-administrado a 57 médicos que trabalhavam nas salas de emergência de dois hospitais de Ribeirão Preto, São Paulo, Brasil, em 2001. Do questionário constaram 38 perguntas sobre conhecimento geral e sobre legislação e atitudes frente ao aborto. A idade média dos entrevistados foi de 28,3; a maioria era do sexo feminino; $52,6 \%$ eram solteiros e $42 \%$, casados; $54,4 \%$ eram católicos e $21 \%$, espiritas. Apesar de a maioria ter bom conhecimento geral sobre o aborto (70\%), um em cada cinco médicos está desinformado sobre o fato de ser o aborto responsável por muitas mortes maternas no Brasil. A maioria aceita as condições do aborto legal e o ampliaria para malformação fetal incompativel com a vida, mas é contra a descriminalização do aborto por outros motivos. O baixo conhecimento sobre as leis do aborto revela-se por conceitos errôneos na aplicação prática do aborto legal. Os resultados sugerem fortemente que muitos não sabem aplicar a lei ou teriam dificuldade para tal.

Aborto Legal; Ética; Serviços de Saúde provavelmente mais fortes do que a capacidade para ensinar direitos humanos nas escolas de medicina.

Verificamos que a maioria concorda com o aborto legal nas condições já existentes, exceto que a lei deveria ser ampliada para casos diagnosticados de malformação incompatível com a vida, idéia que já vem sendo discutida e parece ser bastante aceita na sociedade e entre os médicos 5,22,23,26.

A maioria dos profissionais não aceita a descriminalização do aborto, e encontramos maior rejeição entre os médicos de Ribeirão Preto do que entre os médicos pesquisados por Giffin 8 no Rio de Janeiro, em 1995. Apesar dessa alta rejeição ao aborto provocado, a maioria dos médicos acredita não discriminar nem maltratar suas pacientes quando as atendem nas salas de emergência.

Por ser um direito previsto em lei, a aplicação prática do aborto legal deveria ser mais bem conhecida dos médicos especialistas da área. Por ser um problema de saúde pública, o atendimento ao aborto deveria ser enfatizado nas escolas médicas. Faz-se necessária uma melhora no ensino médico na área de direitos reprodutivos como direitos humanos e de acesso à saúde.

\section{Colaboradores}

E. M. Vieira participou da orientação do projeto, da análise dos dados, da redação, da edição e da revisão do artigo final. D. C. Loureiro contribuiu na revisão de literatura, na elaboração do projeto, na coleta e na análise de dados e na redação do artigo final.

\section{Agradecimentos}

Os autores agradecem ao Conselho Regional de Medicina do Estado de São Paulo, que por meio de seu programa de bolsistas permitiu a realização deste trabalho, e ao Prof. Dr. Geraldo Duarte, chefe do Departamento de Ginecologia e Obstetrícia, Faculdade de Medicina de Ribeirão Preto, Universidade de São Paulo, pelos valiosos comentários a este texto. 


\section{Referências}

1. The Alan Guttmacher Institute. Aborto clandestino: uma realidade latino-americana. New York: The Alan Guttmacher Institute; 1994.

2. Maine D. Does abortion affect later pregnancies? Int Fam Plann Perspect 1979; 5:22-5.

3. Costa SH. 1999 Aborto provocado: a dimensão do problema e a transformação da prática In: Giffin $\mathrm{K}$, Costa SH, organizadores. Questões de saúde reprodutiva. Rio de Janeiro: Editora Fiocruz; 1999. p. 163-84.

4. Corrêa S, Freitas A. Atualizando os dados sobre a interrupção voluntária da gravidez no Brasil. Estudo Fem 1997; 5:389-95.

5. Rocha MIB, Andalaft Neto J. A questão do aborto aspectos clínicos, legislativos e políticos In: Berquó E, organizador. Sexo e vida: panorama da saúde reprodutiva no Brasil. Campinas: Editora Unicamp; 2003. p. 257-318.

6. Coelho HLL, Misago C, Fonseca W, Sousa DSC Selling abortifacients over the counter in pharmacies in Fortaleza, Brazil. Lancet 1991; 338:247.

7. Viggiano MGC, Faúndes A, Borges AL, Viggiano ABF, Souza GR, Rebello I. Disponibilidade de misoprostol e complicações de aborto provocado em Goiânia. J Bras Ginecol 1996; 106:55-61.

8. Giffin K. Aborto provocado: o que pensam os médicos de quatro hospitais públicos do Rio de Janeiro. J Bras Ginecol 1995; 105:121-6.

9. Vieira EM. Do women's attitudes towards abortion and contraceptive methods influence their option for sterilization? Cad Saúde Pública 1999; 15:109-18.

10. Vieira EM. Políticas públicas e contracepção no Brasil. In: Berquó E, organizador. Sexo e vida: panorama da saúde reprodutiva no Brasil. Campinas: Editora Unicamp; 2003. p. 151-96.

11. Pillaye J. Abortion and fertility regulation. Lancet 1996; 398:478.

12. Alegria FVL, Schor N, Siqueira AAF. Gravidez na adolescência: estudo comparativo. Rev Saúde Pública 1989; 23:473-7.

13. Hardy E, Rebello I. La discusión sobre el aborto provocado em el Congresso Nacional Brasileño: el papel del movimento de mujeres. Cad Saúde Pública 1996; 12:259-66.
14. Código Penal. 5a ed. São Paulo: Editora Revista dos Tribunais; 2000

15. Meira AR, Ferraz FRC. Liberação do aborto: opinião de estudantes de medicina e de direito, São Paulo, Brasil. Rev Saúde Pública 1989; 23:456-72.

16. Rezende J. Obstetrícia. 8a Ed. Rio de Janeiro: Editora Guanabara Koogan; 1998.

17. Rocha MIB. A questão do aborto no Brasil: o debate no Congresso. Estudos Fem 1996; 2:381-98.

18. Dallari S. Aborto - um problema ético da saúde pública. Revista de Bioética, 2(1) http://www. cfm.org.br/revista/biolv2/abortprob.html (acessado em 05/Nov/2000).

19. Conselho Regional de Medicina do Estado de São Paulo. Código de Ética Médica. São Paulo: Conselho Regional de Medicina do Estado de São Paulo; 2001.

20. França GV. Comentários ao código de ética médica. Rio de Janeiro: Editora Guanabara Koogan; 1994.

21. Camargo L. Médico diz que Unicamp faz aborto. Folha de São Paulo 1994 Jun 16; Caderno 3-Cotidiano. p. 1.

22. Faúndes A; Bedone A; Pinto e Silva JL. I Fórum interprofissional para implementação do atendimento ao aborto previsto na lei - Relatório final. Femina 1997; 25:1-8.

23. Faúndes A; Oliveira G; Andalaft Neto J; Costa Lopez JR. II Fórum interprofissional para implementação do atendimento ao aborto previsto na lei. Femina 1998; 26:134-8.

24. Naún JC. Abortamento provocado: mini-inquérito de opinião II. Femina 15:573; 1987.

25. Nora JEP, Monteiro RA, Vieira EM. Algumas características das internações por aborto no município de Ribeirão Preto nos anos de 1997 e 1998. In: IV Congresso Médico-Acadêmico. Medicina 2001; 34 Suppl 2:24.

26. Gollop TR. Aborto por anomalia fetal. Bioética 1994; 2:67-72.

Recebido em 27/Mai/2003

Versão final representada em 18/Set/2003 Aprovado em 25/Set/2003 